\title{
MECANISMOS DE LESÄO CEREBRAL NO TRAUMATISMO CRANIOENCEFÁLICO
}

\author{
Almir Ferreira de Andrade', Wellingson Silva Paiva*2, Robson luis Oliveira de Amorim², Eberval Gadelha Figueiredo³, Eloy Rusafa Neto², \\ MANoel Jacobsen Teixeira ${ }^{4}$
}

Trabalho realizado pela divisão de Neurocirurgia do Hospital das Clínicas da Faculdade de Medicina da Universidade de São Paulo, São Paulo, SP

\author{
*Correspondência: \\ Rua DrOvídio Pires de Campos, \\ 171 - apto 511 \\ CEP05403-010 - SãoPaulo-SP \\ wellingsonpaiva@yahoo.com.br
}

\begin{abstract}
RESUMO
O traumatismo cranioencefálico (TCE) é a principal causa de morte e sequela em crianças e adultos jovens nos países industrializados ocidentais. A lesão encefálica definitiva que se estabelece após o TCE é o resultado de mecanismos fisiopatológicos que se iniciam com o acidente e estendem-se por dias ou semanas. As lesões encefálicas no TCE podem ser classificadas em difusas e focais. Esses dois mecanismos costumam associar-se em um mesmo paciente, embora, geralmente exista o predomínio de um tipo. O conhecimento dos mecanismos fisiopatológicos da lesão cerebral no traumatismo cranioencefálico é fundamental para o estabelecimento de medidas terapêuticas clínicas e cirúrgicas. Neste artigo, realizamos uma revisão crítica da literatura sobre os princípios fisiopatológicos da lesão cerebral no paciente com traumatismo cranioencefálico.
\end{abstract}

Unitermos: Trauma. Traumatismos encefálicos. Fisiopatologia. Revisão.

\section{CONSIDERAÇÕES GERAIS}

O traumatismo cranioencefálico (TCE) é a principal causa de morte e sequela em crianças e adultos jovens nos países industrializados ocidentais ${ }^{1,2}$. Nos Estados Unidos, estima-se em torno de 500 mil novos pacientes com TCE por ano. Destes, cerca de 50 mil morrem antes de chegar ao hospital e mais 15 a 20 mil falecem após atendimento hospitalar. Dos cerca de 430 mil restantes, outros 50 mil irão evoluir com sequelas neurológicas de maior ou menor gravidade 3 . Embora a causa principal do TCE varie entre diferentes localidades, os acidentes de trânsito, as quedas e as agressões estão entre suas causas mais frequentes ${ }^{4}$. A taxa de mortalidade também sofre grande variação, sendo mais baixa em países com menor violência no trânsito ${ }^{5}$. Na Europa e América do Norte, a mortalidade anual varia entre 8,4 a 23,6 por 100.000 habitantes 6 .

\section{Fisiopatologia}

A lesão encefálica definitiva que se estabelece após o TCE é o resultado de mecanismos fisiopatológicos que se iniciam com o acidente e se estendem por dias a semanas. Assim, do ponto de vista didático, as lesões cerebrais são classificadas em primárias e secundárias?.

As lesões primárias são aquelas que ocorrem no momento do trauma. No paciente com ferimentos por projétil de arma de fogo ou arma branca que penetram o crânio, a lesão primária ocorre em virtude do trauma direto ao parênquima encefálico. Por outro lado, nos traumatismos fechados, caracterizados quando não ocorre contato com o conteúdo intracraniano, as lesões primárias podem resultar da movimentação cerebral associada à energia cinética do acidente. Nas lesões decorrentes de forças de aceleração e desaceleração não é necessário o impacto do crânio contra estruturas externas. Como o encéfalo e a caixa craniana possuem densidades diferentes, quando submetidos às mesmas forças inerciais, respondem de forma desigual. Esse descompasso de movimentos pode promover a ruptura de veias cerebrais que desembocam nos seios durais, bem como impacto e laceração do parênquima contra as estruturas rígidas do crânio. Somado a esse mecanismo como a região central do encéfalo é relativamente fixa em virtude da presença do tronco encefálico, as regiões periféricas do cérebro e cerebelo tendem a apresentar maior amplitude de movimento. Essa diferença na amplitude dos movimentos entre a região central e a periférica do encéfalo gera o estiramento de axônios e de vasos sanguíneos cerebrais, o que pode resultar desde uma disfunção temporária até ruptura dessas estruturas ${ }^{9}, 10$.

As lesões secundárias decorrem de agressões que se iniciam após o momento do acidente, resultantes da interação de fatores intra e extracerebrais, que se somam para inviabilizar a sobrevivência de células encefálicas poupadas pelo trauma inicial. No local do acidente, intercorrências clínicas como hipotensão arterial, hipoglicemia, hipercarbia, hipóxia respiratória, hipóxia anêmica e distúrbios hidroeletrolíticos são os principais fatores de lesão secundária. Posteriormente, são somados outros distúrbios metabólicos e infecciosos sistêmicos, assim como a presença de substâncias neurotóxicas, hidrocefalia e alterações hemodinâmicas no espaço intracraniano "1, 12. 
Finalmente, existem ainda os mecanismos de morte celular, neuronal, endotelial e glial por distúrbios iônicos e bioquímicos que estão relacionados tanto à lesão primária como à secundária. Entender esses mecanismos é essencial para o estudo das abordagens clínicas e farmacológicas que têm sido utilizadas nos últimos anos. Para melhor compreensão, a fisiopatologia do TCE pode ser dividida nos seguintes tópicos: I) mecanismos de morte celular, II) mecanismos de TCE e III) mecanismos de lesão cerebral após o TCE.

\section{I) Mecanismos de morte celular}

Atualmente são conhecidos dois mecanismos de morte celular, a apoptose e a necrose ${ }^{13}$. A característica central da morte por apoptose é a quebra da fita de DNA internucleossomal. Técnicas para a identificação dessas estruturas em cortes histológicos têm sido utilizadas extensivamente nos últimos anos. A microscopia eletrônica evidencia edema celular e mitocondrial, vacuolização citoplasmática e núcleos picnóticos ${ }^{14,15}$.

A apoptose é a manifestação morfológica da morte programada, utilizada em situações fisiológicas como no processo de maturação do sistema nervoso, no qual neurônios que não desenvolveram sinapses relevantes são descartados ${ }^{16}$. A morte celular por apoptose tem a vantagem de suscitar pouca reação inflamatória, o que minimiza lesão tecidual; por outro lado, como é um mecanismo fisiológico, despende de energia. A apoptose pode ser deflagrada por estímulos conhecidos como a lesão parcial do DNA, o glutamato e o estresse oxidativo. Por outro lado, todos esses fatores também podem levar a necrose neuronal. No TCE podemos encontrar lesões por apoptose tanto em sítios perilesionais como em estruturas distantes do trauma como o tálamo e o hipocampo ${ }^{17}$. Apesar de bem documentada, a apoptose parece ser responsável por apenas uma pequena parte das mortes neuronais no TCE, logo, sua utilização como possível alvo de novas abordagens terapêuticas, ainda está para ser estabelecida ${ }^{18,19}$.

A necrose é o principal mecanismo de morte celular no TCE. Ao contrário da apoptose, na qual a célula comanda ativamente o processo de sua destruição, na necrose existe uma falência energética e a morte ocorre pela incapacidade da célula de manter sua homeostase. Dessa maneira, é um processo menos organizado e que envolve uma resposta inflamatória de maior intensidade ao seu redor. Os mais conhecidos estímulos que levam a necrose são a excitotoxicidade e o estresse oxidativo.

A excitotoxicidade é o mecanismo pelo qual o glutamato e outros neurotransmissores excitatórios causam lesão celular ${ }^{20}$. Os níveis de glutamato elevam-se no trauma por vários caminhos. Em um primeiro momento, a energia cinética do TCE causa deformação mecânica nos axônios, que, por sua vez, leva à despolarização das membranas celulares e liberação de neurotransmissores, dentre eles o glutamato. Em um segundo momento, outros fatores, como a hipóxia, o estresse oxidativo e a própria despolarização gerada pela excitotoxicidade podem comprometer o controle da permeabilidade da membrana e aumentar ainda mais a presença do glutamato extracelular. O glutamato liga-se tanto a receptores acoplados a canais iônicos de $\mathrm{Ca}^{++}$ e $\mathrm{Na}^{+}$, os mais importantes são os chamados Kainato, NMDA e AMPA, como a receptores acoplados a sistemas de segundo mensageiro, chamados metabotrópicos ${ }^{21}$. Nos mecanismos de excitotoxicidade, os receptores ionotrópicos são os mais estudados. A lesão celular na excitotoxicidade ocorre em dois estágios. Em um primeiro momento ocorre um influxo de $\mathrm{Na}^{+}$com consequente edema celular. Em um segundo momento, a abertura de canais de $\mathrm{Ca}^{++}$de longa duração leva ao acúmulo excessivo de cálcio intracelular. O acúmulo de cálcio, por sua vez, é capaz de promover a ativação de proteases, fosfolipases e óxido nítrico que desencadeiam uma série de eventos que culminam com a morte celular22. A ativação da fosfolipase $A$ aumenta a permeabilidade da membrana, gera a formação de ácido aracdônico (AA) e radicais livres.

O estresse oxidativo é o resultado da ação de radicais livres no tecido. No TCE, a hipóxia é o principal fator para o acúmulo de radicais livres, embora o glutamato, como visto acima, contribua para esse quadro pela ativação da fosfolipase $A$. Os radicais livres lesam a célula por diferentes mecanismos. Na membrana eles inibem a bomba de $\mathrm{Na}^{+} / \mathrm{K}^{+}$, oxidam a dupla camada de lipídeos e hidrolisam fosfolípides. Essas ações levam ao aumento da permeabilidade da membrana que favorece o acúmulo de cálcio intracelular e liberação de glutamato. Ao hidrolisar fosfolípides levam também a formação de AA, cujas consequências foram descritas acima ${ }^{23}$.

O óxido nítrico (NO) é produzido pelo aumento na concentração do cálcio intracelular associado aos mecanismos de agressão celular presentes no trauma. No TCE, sua ação pode ser dividida em três fases: antes de 30 minutos, entre 30 minutos e seis horas e após seis horas. $\mathrm{Na}$ primeira fase, o NO parece agir preservando o fluxo sanguíneo cerebral (FSC). Em um segundo tempo existe uma depleção do NO acompanhado de diminuição do FSC. Após seis horas, o NO volta a aumentar. Nessa última fase, o acúmulo de $\mathrm{NO}$ acomete o endotélio, causando uma potente vasodilatação e aumento da permeabilidade vascular. A combinação dessas ações leva ao aumento do FSC, da PIC e do edema cerebrall24.

\section{II) Mecanismos de TCE}

As lesões encefálicas no TCE podem ser separadas em: A) difusas e B) focais. Esses dois mecanismos costumam estar associados em um mesmo paciente, embora, geralmente, exista o predomínio de um tipo.

\section{A) Lesões difusas}

As lesões difusas são aquelas que acometem o cérebro como um todo e, usualmente, decorrem de forças cinéticas que levam a rotação do encéfalo dentro da caixa craniana. Podem ser encontradas disfunções por estiramento ou ruptura tanto de axônios como de estruturas vasculares em regiões distintas do encéfalo.

Dentre as lesões difusas, o termo concussão cerebral é utilizado atualmente para se referir a perda temporária da consciência associada ao TCE ${ }^{25,26}$. Genarelli et al. ${ }^{27}$ usando parâmetros clínicos, dividiram a concussão cerebral em leve e moderada. A concussão leve engloba os casos com distúrbios neurológicos completamente reversíveis, sem perda da consciência, e pode ser dividida em três subgrupos. $O$ primeiro subgrupo é constituído por pacientes que apresentam confusão e desorientação mental que duram segundos, sem amnésia. No segundo, os pacientes desenvolvem amnésia retrógrada de cinco a dez minutos e no terceiro subgrupo os pacientes desenvolvem amnésia retrógrada e anterógrada. 


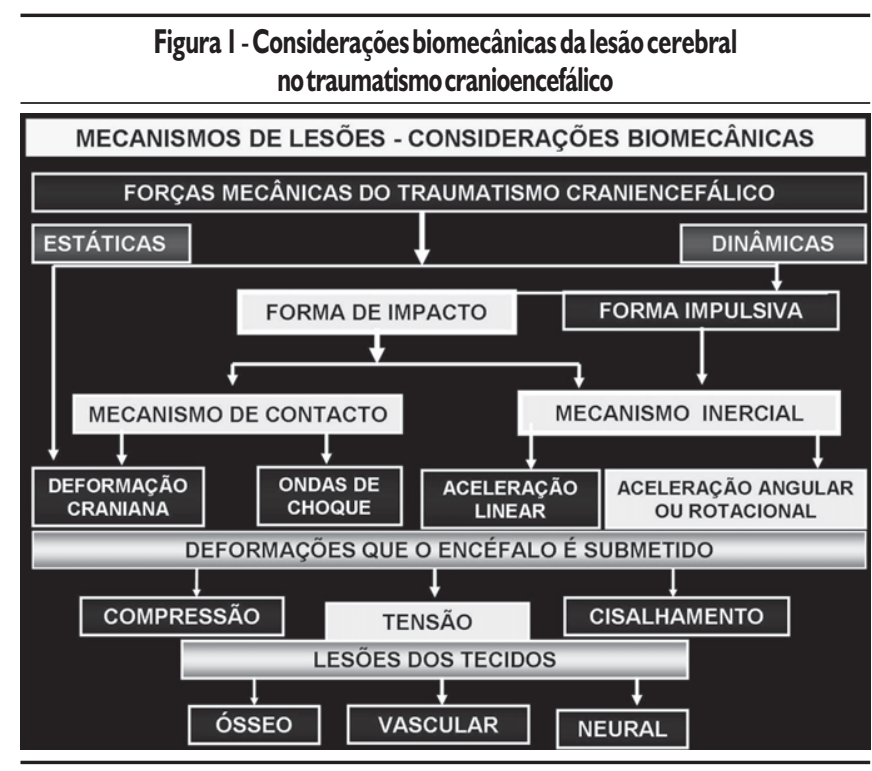

Figura 2-Mecanismo físico e abertura dos canais da menbrana celular eaxonal com influxo de cálcio no traumatismo cranioencefálico

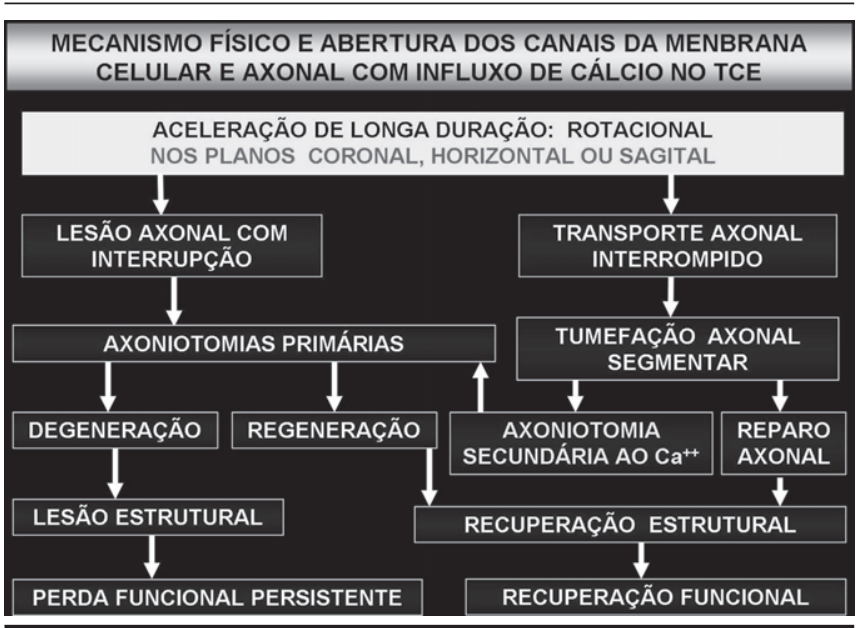

Ca $=$ cálcio

TCE $=$ Traumatismo cranioencefálico

Os mecanismos que levam à perda da consciência não estão totalmente esclarecidos, embora existam evidências que a distorção mecânica das membranas celulares possa abrir canais iônicos, gerando uma disfunção transitória cerebral27, 28. Corroborando com essa hipótese, sabe-se atualmente que pessoas com mutações genéticas específicas em canais de cálcio apresentam maior risco de desenvolver lesões cerebrais após traumatismos leves ${ }^{29,30}$.

A lesão axonal difusa (LAD), como descrito por Genarelli'27, referese à perda de consciência por mais de seis horas, associada ao TCE, sem distúrbio metabólico ou lesão expansiva visível na tomografia que justifiquem o quadro. Na LAD, a tomografia pode ser normal ou apresentar pequenos pontos hemorrágicos próximos aos núcleos da
Figura 3-Eventosfisiopatológicos nas lesões difusas no traumatismo cranioencefálico, atuação de canaisiônicos e efeito excitotóxico do glutamato

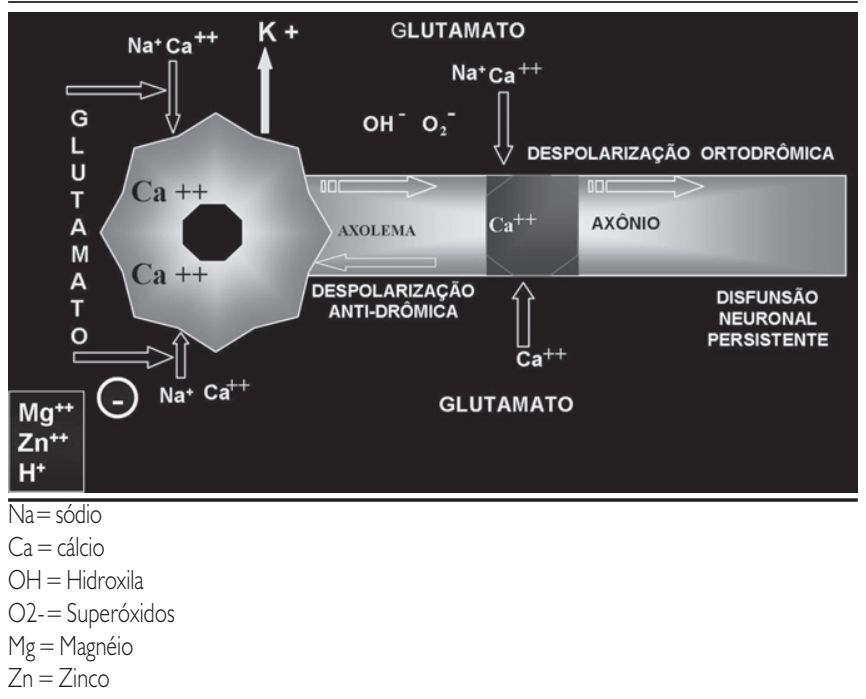

base, no tronco ou na região parassagital. Acredita-se que o mecanismo que dá origem a LAD é o estiramento axonal decorrente do movimento de rotação do encéfalo no momento do trauma. No entanto, a lesão desenvolve-se e estabelece-se somente após uma sequência de eventos que pode durar horas. Ocorrendo um bloqueio no transporte axonal desencadeado pela lesão de estruturas intracelulares, que leva ao surgimento de edema local e, finalmente, ruptura do axônio ${ }^{3 !}$.

Nas lesões difusas, a tumefação cerebral foi considerada por anos como decorrente da perda no controle dos mecanismos do tônus vascular. Acreditava-se que isso levaria a um aumento descontrolado do fluxo sanguíneo cerebral (FSC), que causaria o ingurgitamento hemisférico uni ou bilateral. Dessa maneira, não haveria um edema verdadeiro, pois não haveria acúmulo de líquido no espaço intersticial². Atualmente, esse conceito tem sido revisto e as evidências acumulamse no sentido da tumefação cerebral ser interpretada novamente como uma combinação de edema celular e vasogênico, frutos de um distúrbio extremo na permeabilidade da membrana celular, provavelmente associado a canais de água, as aquaporinas ${ }^{33,34}$

A tumefação cerebral pode ser hemisférica $(\mathrm{TCH})$ ou bi-hemisférica, também chamada de difusa (TCD). A TCH frequentemente associa-se à lesões focais como o hematoma subdural agudo (HSDA) e pode causar herniação cerebral ${ }^{13}$.

O Traumatic Coma Data Bank da Brain Trauma Foundation ${ }^{13}$ classifica as lesões difusas em quatro tipos, de acordo com os achados na tomografia de crânio (TC): (I) Sem alteração visível na TC de admissão; (II) TC com as cisternas basais cerebrais presentes e desvio das estruturas da linha mediana (DLM) de até $5 \mathrm{~mm}$, sem lesão de alta ou mista densidade maior que $25 \mathrm{~cm}^{3}$; (III) TC com cisternas comprimidas ou ausentes e DLM de 0 a 5 mm sem lesão de alta ou mista densidade maior que $25 \mathrm{~cm}^{3}$ (bi-hemisférica) e (IV) pacientes que apresentavam TC com DLM maior que $5 \mathrm{~mm}$ sem lesão de alta ou mista densidade maior que $25 \mathrm{~cm}^{3}$ (hemisférica). 
ANDRADEAFETAL.

\section{B) Lesões focais}

As lesões focais são compostas por hematomas - intra ou extracerebrais - ou áreas isquêmicas delimitadas que acometem apenas uma região do cérebro. Nas lesões puramente focais, presume-se que 0 restante do encéfalo mantenha suas propriedades de complacência tecidual e vascular preservadas.

Dentre as lesões focais, as fraturas cranianas podem ser lineares ou associadas a afundamento focal. Elas decorrem de traumas com baixa energia cinética, onde existe o contato da cabeça contra estruturas rígidas externas ${ }^{35}$. As fraturas lineares costumam ser consequência de traumas que deformam a abóbada craniana enquanto os afundamentos refletem uma colisão mais pontual. As fraturas lineares isoladas não causam danos cerebrais, porém, elas podem estar associadas a lesões de estruturas vasculares que causam complicações potencialmente fatais, como os hematomas extradurais. Nos casos em que ocorre a abertura da dura-máter, o paciente passa a apresentar também risco de fístula liquórica, meningite e abscesso cerebral. Em crianças com menos de um ano de idade, pode existir ainda um tipo especial de fratura com afundamento, a fratura em "ping-pong". Nesse tipo de afundamento, o local da calota craniana que recebe o impacto afunda e torna-se côncavo, sem a formação de espículas ósseas. Usualmente, não há lesão da dura máter ou do cérebro subjacente e a cirurgia tem indicações estéticas ${ }^{36,37}$.

O hematoma extradural (HED), na maioria dos casos, resulta de impacto craniano com baixa energia cinética. Para que o sangramento ocorra, é necessário o rompimento de estruturas vasculares localizadas no espaço epidural, o que normalmente ocorre junto a linhas de fratura. Embora as fraturas cranianas ocorram em até $90 \%$ dos pacientes com HED, sua ausência não exclui a presença do sangramento ${ }^{38}$. Quando o HED ocorre na fossa posterior esse risco é ainda maior ${ }^{39,40 .}$

Já o hematoma subdural agudo (HSDA) está associado a mecanismos de aceleração e desaceleração dos traumas com grande energia cinética e, do mesmo modo das lesões difusas cerebrais, não necessita do contato do crânio com estruturas externas para ser gerado ${ }^{4 !}$. Devido a essas semelhanças, pacientes com HSDA também apresentam, frequentemente, lesões cerebrais difusas, o que piora de maneira significativa seu prognóstico. Nos HSDA, ao contrário das lesões difusas puras, veias corticais rompem e sangram durante 0 movimento de rotação cerebral. A presença de sangue no espaço subdural, em íntimo contato com o córtex, pode desencadear lesões secundárias associadas à excitotoxicidade ${ }^{42}$.

A contusão cerebral é composta de áreas hemorrágicas ao redor de pequenos vasos e tecido cerebral necrótico. Usualmente, a hemorragia inicia-se na superficie dos giros, que é onde ocorre o maior atrito entre o cérebro e as estruturas rígidas do crânio. Os mecanismos de formação das contusões podem ser decorrentes da agressão direta do parênquima, como no caso das fraturas com afundamento craniano, ou pelo movimento do encéfalo dentro da caixa craniana, que pode levar ao esmagamento do parênquima contra a base do crânio ou outras estruturas rígidas. Quando ocorre a ruptura da pia-máter, a contusão passa a ser chamada de laceração. Os locais mais comuns das contusões nos traumatismos fechados são a base do lobo frontal, a ponta do lobo temporal e a região ao longo da foice. A base do lobo frontal propicia a formação de contusões devido a sua superfície irregular e pelo fato de ser a região onde o cérebro se apóía tanto nos movimentos de rotação como nos de translação associados ao traumatismo. O lobo temporal, devido a sua anatomia, também favorece ao comprometimento de sua ponta contra os ossos da fossa média e da asa do esfenóide. A região ao longo da foice costuma ser afetada em acidentes em que ocorre movimento de translação e o cérebro, deslizando no sentido ântero-posterior, sofre múltiplas contusões nos pontos mais altos de sua convexidade. Uma vez estabelecida a lesão, forma-se uma área edema ao seu redor, que pode crescer durante vários dias e gerar importante efeito de massa. O pico do edema costuma ocorrer em torno do terceiro dia após o trauma. Depois disso, a tendência da lesão é ser absorvida resultando em uma cicatriz atrófica local42.

\section{III) Mecanismos de lesão cerebral após o TCE}

As lesões secundárias são decorrentes de processos que contribuem para morte celular após o trauma inicial. Seus principais elementos são a hipóxia, distúrbios metabólicos, distúrbios hidroeletrolíticos e hipertensão intracraniana.

O cérebro é nutrido essencialmente pela oxidação da glicose. Seu alto metabolismo faz com que consuma, em situações fisiológicas, cerca de $20 \%$ do oxigênio e $25 \%$ da glicose utilizada pelo organismo ${ }^{2}$. O aporte de oxigênio às células do SNC depende do fluxo sanguíneo cerebral (FSC), da saturação de $\mathrm{O}_{2}$ da concentração de hemoglobina no sangue e da capacidade de troca gasosa pelos capilares. Fatores associados ao TCE como obstrução de vias aéreas, traumatismo pulmonar, choque e hipovolemia podem contribuir para a diminuição de oferta de oxigênio ao tecido cerebral. Associado ainda, distúrbios da microcirculação que comprometem a troca gasosa entre as hemácias e o tecido podem ocorrer por perda da autorregulação vascular ou processos inflamatórios. A diminuição do aporte de energia força a célula a utilizar vias anaeróbias, que, por sua vez, aumentam a concentração de radicais livres e glutamato, amplificando a destruição celular intracraniana. Tanto a hipoglicemia, que priva a célula de nutrientes como a hiperglicemia, que causa acidose tecidual, podem contribuir para o dano cerebral2.

Em situações fisiológicas, o organismo mantém um FSC constante, entre 40 e 60ml por $100 \mathrm{~g}$ por minuto, dentro de uma variação da pressão arterial média (PAM) entre 60 e $150 \mathrm{mmHg}$. Para manter essa perfusão constante, os vasos intracranianos contraem e dilatam de acordo com a necessidade. Quando a PAM fica abaixo dos limites citados acima, pode haver hipoperfusão tecidual. Por outro lado, quando a PAM ultrapassa esses limites existe risco de dano cerebrovascular, com lesão da musculatura lisa vascular e perda da barreira hematoencefálica. O FSC passa, então, a variar livremente de acordo com a PAM ${ }^{40}$.

No TCE, o FSC deve ser avaliado pela pressão de perfusão cerebral (PPC), que é calculada pela PAM menos a pressão intracraniana (PIC). Como o cérebro é confinado em uma caixa óssea rígida e a PPC é dependente da $\mathrm{PIC}$, o controle da hipertensão intracraniana $(\mathrm{HIC})$ assume papel de máxima importância no TCE. 
A teoria de Monro-Kellie, de 1783, modificada por Burrows em 1846, estabelece que o crânio adulto é um sistema inextensível e que seu volume total é constante. Reconhece-se hoje que $80 \%$ desse volume é composto de tecido neural, $10 \%$ de sangue e $10 \%$ de líquido cefalorraquiano. Alterações volumétricas dos componentes, individualmente, levam a alterações recíprocas nos demais, de modo a manter o volume intracraniano constante ${ }^{43}$.

Em situações normais, o líquido cefalorraquiano é o primeiro componente a se deslocar para o espaço subaracnóideo espinhal, seguindo-se do sangue para os seios venosos, permanecendo o cérebro relativamente incompressível. A pressão intracraniana permanece relativamente constante com os acréscimos de volume intracraniano desde que não se esgotem as reservas de líquido cefalorraquiano e sangue ${ }^{43}$.

A elastância é definida a partir do aumento da PIC (pressão intracraniana) por unidade de volume acrescentado ao compartimento intracraniano, e a complacência é o inverso da elastância e definida a partir do volume necessário para elevar uma unidade de PIC, medida pela comparação entre os diferentes volumes necessários em diversas situações para elevar a PIC em uma unidade. Define-se, pois, uma fase de baixa elastância e alta complacência enquanto houver deslocamentos de volumes intracranianos, e uma fase de alta elastância e baixa complacência quando se esgotam tais reservas - curva de Lanfilt de pressão $x$ volume intracraniano ${ }^{44}$.

No TCE, a presença de elementos como hematomas, contusões, edema, acúmulo de LCR ou aumento do volume intravascular, que superam a capacidade de acomodação intracraniana, elevam a $\mathrm{PIC}^{45}$.

$\mathrm{O}$ valor normal de PIC em adultos é cerca de $15 \mathrm{mmHg}$. Em posiçãa deitada, os valores de pressão intraventricular e lombar são iguais. Na posição ereta, a pressão lombar pode atingiir valores de 20 a $30 \mathrm{mmHg}$, a depender da altura do paciente ${ }^{45}$.

Há elevações transitórias da PIC em situações de esforços físicos ou respiratórios (tosse, evacuação, posição de Trendelemburg) que são bem toleradas se a complacência intracraniana for elevada. Outras variações temporais da PIC foram descritas, por seu caráter cíclico, como ondas de Lundberg. As ondas A, sempre patológicas, também conhecidas como ondas em platô, são elevações da PIC da ordem de até $100 \mathrm{mmHg}$ durante 2 a 20 minutos, com queda abrupta ao valor basal, e são interpretadas como sinais de grave descompensação da $\mathrm{PIC}^{46}$. São consideradas eventos pré-terminais quando aumentam em frequência e amplitude. As ondas B ocorrem I a 2 vezes por minuto, com amplitude de até $50 \mathrm{mmHg}$, refletindo a influência do ciclo respiratório sobre a PIC. São considerados sinais de alerta porque demonstram algum grau de prejuízo da complacência cerebral. As ondas $\mathrm{C}$ ocorrem de 4 a 8 vezes por minuto e refletem as curvas arteriais de Traube-Hering-Meier ${ }^{47}$.

Valores persistentes da PIC maiores de $15 \mathrm{~mm} \mathrm{Hg}$ são considerados anormais, quando se encontram entre 20 e $40 \mathrm{~mm} \mathrm{Hg}$, indicam $\mathrm{HIC}$ moderada, acima de $40 \mathrm{~mm} \mathrm{Hg}$ representam HIC grave com risco de morte ${ }^{3}$. Níveis de HIC mantidos acima de $60 \mathrm{~mm} \mathrm{Hg}$ sinalizam ausência de fluxo cerebral e são quase sempre fatais. A HIC se desenvolve em aproximadamente $50 \%$ de todos os TCE graves e é mais comum naqueles com lesão expansiva intracraniana. A HIC foi encontrada em $71 \%$ dos pacientes operados com hematoma intracerebral e $39 \%$ dos pacientes com HSDA e HED ${ }^{48}$.

Dentre as causas de HIC, a que traz maiores desafios é o edema, que tem fisiopatologia e manuseio complexos. Existem cinco tipos principais de edema: citotóxico, vasogênico, hidrostático, intersticial e osmótico $^{49}$.

O edema citotóxico é um processo intracelular afetando, particularmente, os astrócitos. Sua causa é a ausência do aporte de energia, que interfere com os mecanismos da bomba iônica na membrana celular e leva ao acúmulo de $\mathrm{Na}^{+}$intracelular e consequente edema. A formação desse edema está intimamente ligada a níveis críticos do FSC. O processo começa com a perda da atividade elétrica quando o FSC cai abaixo de $40 \%$ do basal. Quando - FSC cai abaixo de $20 \%$ do normal, há falência dos mecanismos da bomba iônica da membrana celular. Esse tipo de edema é frequentemente encontrado ao redor de contusões cerebrais ou no infarto do território vascular ${ }^{50,51}$

O edema cerebral vasogênico resulta de distúrbio na barreira hematoencefálica permitindo a passagem de água, sódio e proteína para dentro do espaço intersticial. O edema é formado na substância cinzenta, mas pode acumular-se na substância branca. A taxa de formação do edema é aumentada pela hipertensão arterial e aumento da temperatura corporal. Fatores inflamatórios que aumentam a permeabilidade vascular podem contribuir para esse processo $0^{51}$.

O edema hidrostático também é devido ao acúmulo de líquido extracelular pobre em proteína, porém é considerado como resultado de aumento abrupto na diferença de pressão hidrostática entre os espaços intra e extravascular. No TCE, isso pode ocorrer seguindo descompressão súbita de uma lesão expansiva, que causa redução aguda da PIC e aumento abrupto da pressão transmural da vasculatura cerebral. Isso também pode ocorrer quando a autorregulação vascular se altera pelo trauma e existe um concomitante aumento da pressão arterial. Assim, a pressão transmural na rede capilar é abruptamente elevada ${ }^{50,51}$.

O edema intersticial é uma complicação da obstrução do fluxo do LCR que ocorre na hidrocefalia. $\mathrm{O}$ aumento da pressão intraventricular força a infiltração de LCR no tecido periventricular ${ }^{50,51}$. O edema osmótico é resultante de queda da osmolaridade plasmática usualmente associado à hiponatremia. A relação entre níveis particulares do sódio plasmático e a formação do edema cerebral é complexa e relacionada à velocidade de desenvolvimento e duração da hiponatremia ${ }^{51}$.

\section{Conclusão}

O conhecimento dos mecanismos fisiopatológicos da lesão cerebral no traumatismo cranioencefálico é fundamental para o estabelecimento de medidas terapêuticas clínicas e cirúrgicas diante dos quadros emergenciais, geralmente envolvendo decisões rápidas e fundamentadas. Ressalta-se, assim, a importância na formação dos profissionais envolvidos no atendimento de emergência, em especial os neurocirurgiões e cirurgiões de trauma.

\section{Conflito de interesse: não há}




\section{SUMMARY \\ THE PATHOPHYSIOLOGICAL MECHANISMS FOLLOWING TRAUMATIC BRAIN INJURY}

Traumatic brain injury is the main cause of death and disability in children and adults in Western Countries. The definitive brain injury is a consequence of pathophysiologicalmechanisms that begin at the moment of an accident and may extend for days or weeks. Traumatic brain injury may be classified as diffuse or focal. These two mechanisms are commonly associated in a patient, however one is generally predominant. Therefore knowledge of the pathophysiological mechanisms of brain injury in head trauma is important to establish the therapeutic, clinical and surgical measures. In this paper the authors present a critical review of the literature on the pathophysiological principles of traumatic brain injury. [Rev Assoc Med Bras 2009; 55(I): 75-8I]

KeY wORDS: Trauma. Brain injuries. Physiopathology. Review.

\section{REFERÊNCIAS}

I. Kraus JF. Epidemiology of head injury. In: Cooper PR, editor. Head injury. 3a ed. Baltimore: Willians \& Wilkins; 1993. p. I-25.

2. McArthur DL, Chute DJ, Villablanca JP. Moderate and severe traumatic brain injury: epidemiologic, imaging and neuropathologic perspectives. Brain Pathol. 2004; 14:185-94.

3. Kelly DF, Doberstein C, Becker DP. General principles of head injury management. In: Narajan RK, Wilberger JE, Povlishok JT, editors. Neurotrauma. New York: Mc Graw-Hill; 1996. p.7l-I01.

4. Adekoya N, Majumder R. Fatal traumatic brain injury, West Virginia, 1989-1998. Public Health Rep. 2004; I19:486-92.

5. Cameron PA, Rainer TH, Mak P. Motor vehicle deaths in Hong Kong: opportunities for improvement. J Trauma. 2004;56:890-3.

6. Firsching R, Woischneck D. Present status of neurosurgical trauma in Germany. World J Surg. 2001;25:1221-3.

7. Engberg AW, Teasdale TW. A population-based study of survival and discharge status for survivors after head injury. Acta Neurol Scand. 2004; I 10:281-90

8. Goodman JC, - Pathophysiology - mild and moderate brain injuries In Marion DW, editor. Traumatic brain injury. New York: Thieme; 1999. p. 143-54.

9. Mendelow AD, Teasdale G, Jennet B, Bryden J, Hessett C, Murray G: Risks of intracranial haematoma in head injured adults. Br Med J. 1983;287: 1 173-6.

I 0. Teasdale G, Mathew P. Mechanisms of cerebral concussion, contujsion and other effects of head injury. In: Youmans JR, editor. $4^{\text {th }}$ ed., Philadelphia, WB Saunders; 1996. p.I533-48.

I I. Meixensberger J, Kunze E, Barcsay E, Vaeth A, Roosen K. Clinical cerebral microdialysis: brain metabolism and brain tissue oxygenation after acute brain injury. Neurol Res. 2001 ;23:80I-6.

12. Cochran A, Scaife ER, Hansen KW, Downey EC. Hyperglycemia and outcomes from pediatric traumatic brain injury. I Trauma. 2003;55: 1035-8.

13. Raghupathi R. Cell death mechanisms following traumatic brain injury. Brain Pathol. $2004 ; \mid 4: 215-22$.

14. Ng I, Yeo TT, Tang WY, Soong R, Ng PY, Smith DR. Apoptosis occurs after cerebral contusions in humans. Neurosurgery. 2000;46:949-56.

I 5. Kochanek PM, Clark RS, Ruppel RA, Adelson PD, Bell MJ, Whalen MJ, et al. Biochemical, cellular, and molecular mechanisms in the evolution of secondary damage after severe traumatic brain injury in infants and children: lessons learned from the bedside. Pediatr Crit Care Med. 2000;1:4-19.

16. Keane RW, Kraydieh S, Lotocki G, Alonso OF, Aldana P, Dietrich WD. Apoptotic and antiapoptotic mechanisms after traumatic brain injury. J Cereb Blood Flow Metab. 2001;21:1189-98.
17. Nau R, Haase S, Bunkowski S, Bruck W. Neuronal apoptosis in the dentate gyrus in humans with subarachnoid hemorrhage and cerebral hypoxia. Brain Pathol. 2002;12:329-36.

18. Polster BM, Fiskum G. Mitochondrial mechanisms of neural cell apoptosis. J Neurochem. 2004;90:1281-9.

19. Maragos WF, Korde AS. Mitochondrial uncoupling as a potential therapeutic target in acute central nervous system injury. J Neurochem. 2004;91:257-62.

20. Lipton SA, Rosenberg PA. Excitatory amino acids as a final common pathway for neurologic disorders. N Engl J Med. 1994;330:613-22.

21. Bruno V, Battaglia G, Copani A, D'Onofrio M, Di lorio P, De Blasi $A$, et al. Metabotropic glutamate receptor subtypes as targets for neuroprotective drugs. J Cereb Blood Flow Metab. 2001;21:1013-33.

22. Nathoo N, Chetry R, Van Dellen JR, Connolly C, Naidoo R. Apolipoproyein E polymorphism and outcome after closed traumatic brain injury: influence of ethnic and regional differences. J Neurosurg. 2003;98:302-6.

23. Wilson JX, Gelb AW. Free radicals, antioxidants, and neurologic injury: possible relationship to cerebral protection by anesthetics.J Neurosurg Anesthesiol. 2002; 14:66-79.

24. Cherian L, Hlatky R, Robertson CS. Nitric oxide in traumatic brain injury. Brain Pathol. 2004;14:195-201.

25. McCrory PR, Berkovic SF. Concussion: the history of clinical and pathophysiological concepts and misconceptions. Neurology. 200I; 57:2283-9.

26. McCrory P. When to retire after concussion? Br J Sports Med. 2001;35:380-2.

27. Gennarelli TA, Graham DI. Neuropathology of the head injuries. Semin Clin Neuropsychiatry. 1998;3:160-75.

28. Gennarelli T, Thibault L, Graham D. Diffuse axonal injury: and important form of traumatic brain damage. Neuroscientist 1998;4:202-15.

29. Kors EE, Terwindt GM, Vermeulen FL, Fitzsimons RB, Jardine PE, Heywood P, et al. Delayed cerebral edema and fatal coma after minor head trauma: role of the CACNAIA calcium channel subunit gene and relationship with familial hemiplegic migraine. Ann Neurol. 200I;49:753-60.

30. Jordan B, Relkin N, Ravdin L. Apolipoprotein E epsilon 4 associated with chronic traumatic brain injury in boxing. JAMA. 1997;278:136-40.

31. Medana IM, Esiri MM. Axonal damage: a key predictor of outcome in human CNS diseases. Brain. 2003;126:515-30.

32. Obrist WD, Gennarelli TA, Segawa H. Relation of cerebral blood flow to neurological status and outcome in head injured patients. I Neurosurg. 1979;51:292-300.

33. Marmarou A. Pathophysiology of traumatic brain edema: current concepts. Acta Neurochir Suppl. 2003;86:7-I0.

34. Badaut J, Lasbennes F, Magistretti PJ, Regli L. Aquaporins in brain: distribution, physiology, and pathophysiology. J Cereb Blood Flow Metab. 2002;22:367-78.

35. Masters SJ, McClean PM, Arcarese JS. Skull x-ray examinations after head trauma. Recommendations by a multidisciplinary panel and validation study. N Engl J Med. |987;316(2):84-9|

36. Francel P, Alves WM, Jane JÁ. Mild head injury in neurological surgery. In: Youmans JR, editor. Neurological surgery. $4^{\text {th }}$ ed. Philadelphia: WB Saunders; 1996. p.I595-6I7.

37. Aldrich EF, Levin HS, Eisenberg HM. Mild head injury in children. In: Youmans JR, editor. Neurological surgery. $4^{\mathrm{a}}$ ed. Philadelphia: WB Saunders; 1996. p.1719-29.

38. Baykaner K, Alp H, Ceviker N, Keskil S, Seckin Z. Observation of 95 patients with extradural hematoma and review of the literature. Surg Neurol. $1988 ; 30: 339-41$.

39. Bor-Seng-Shu E, Aguiar PH, Almeida Leme RJ, Mandel M, Andrade AF, Marino Jr. R. Epidural hematomas of the posterior cranial fossa Neurosurg Focus. 2004; 16:ECPI. 
40. Bor-Seng-Shu E, Hirsch R, Teixeira MJ, Andrade AF, Marino R Jr. Cerebral hemodynamic changes gauged by transcranial Doppler ultrasonography in patients with posttraumatic brain swelling treated by surgical decompression. J Neurosurg. 2006; 104(1):93-100

4I. Teasdale G, Mathew P. Mechanisms of cerebral concussion, contusion and other effects of head injury. In: Youmans JR, editor. Neurological surgery. $4^{\text {th }}$ ed. Philadelphia: WB Saunders; 1996. p. $1533-48$.

42. Sawauchi S, Murakami S, Ogawa T, Abe T Mechanism of injury in acute subdural hematoma and diffuse brain injury: analysis of 587 cases in the Japan Neurotrauma Data Bank. No Shinkei Geka. 2007;35:665-7I.

43. Uzzell BP, Obrist WD, Dolinskas CA, Langfitt TW. Relationship of acute $\mathrm{CBF}$ and ICP findings to neuropsychological outcome in severe head injury. J Neurosurg. 1986;65:630-5.

44. Obrist WD, Langfitt TW, Jaggi JL, Cruz J, Gennarelli TA. Cerebral blood flow and metabolism in comatose patients with acute head injury. Relationship to intracranial hypertension. I Neurosurg. 1984;61:241-53.

45. Chesnut RM, Marshall LF, Klauber MR. The role of secondary brain injury in determining outcome from severe head injury. J Trauma. 1993;34:216-22.
46. Rosner MJ, Becker DP. Origin and evolution of plateau waves: experimental observations and a theoretical model. J Neurosurg. 1984;60:312-24.

47. Czosnyka M, Smielewski P, Piechnik S. Hemodynamic characterization of intracranial pressure plateau waves in head-injured patients. J Neurosurg. 1999;91:11-9.

48. Saul TG, Ducker TB. Effect of intracranial pressure monitoring and aggressive treatment on mortality in severe head injury. J Neurosurg. 1982;56:498-503.

49. Miller JD. Traumatic brain swelling and edma. In: Cooper PR, editor. Head injury. $3^{\text {rd }}$ ed. New York: Springer Verlag; 1993. p.33।-54.

50. Miller JD. Brain edema in head injury. In: Cohadon F, Baethmann A, GO KG, Miller JD, editors. Traumatic brain edema. New York: SpringerVerlag; 1987. p.99-I03.

51. Safar P. Ressucitation of the ischemic brain. In: Albin MS, editor. Textbook of neuroanesthesia with neurosurgical and neuroscience perspectives. New York: Mc Graw-Hill; 1997. p.557-93.

Artigo recebido: 29/1 I/07

Aceito para publicação: 19/04/08 